\title{
Minireview
}

\section{Targeting the mammalian target of rapamycin (mTOR): a new approach to treating cancer}

\author{
S Chan ${ }^{*, 1}$ \\ 'Consultant Oncologist, The City Hospital, Nottingham NG5 IPB, UK
}

mTOR is a downstream mediator in the PI3KJAkt signalling pathway, which plays a critical role in regulating basic cellular functions. These include cell proliferation, survival, mobility and angiogenesis. Rapamycin and its analogues (CCI-779, RAD00I and AP23573) have specific antagonistic action on the function of mTOR. This leads to inhibition of the downstream signalling elements and results in the cell cycle arrest in the GI phase. This group of drugs may have a place in Oncology for the treatment of cancers, which occur as a result of increased activity of the PI3 kinase/Akt/m-TOR pathway. The basic structure of the pathway was reviewed in this article, together with results of the clinical studies targeting mTOR for cancer therapy. This is an exciting area for development and poses many challenges to researchers.

British Journal of Cancer (2004) 9 I, |420- |424. doi:I0.1038/sj.bjc.6602 I 62 www.bjcancer.com

Published online 14 September 2004

(c) 2004 Cancer Research UK

Keywords: PI3K pathway; PTEN; Akt; m-TOR; CCI-779; Rapamycin

\section{THE PI3-KINASES, AND mTOR}

The phosphoinositide 3-kinase (PI3K) family of enzymes is responsible for the production of 3-phosphoinositide lipid second messengers including phosphoinositol trisphosphate (PIP3). The pathway controls a cascade of signals that regulates many basic cellular properties, including proliferation, survival, motility, and angiogenesis. Evidence implicating the role of deregulation of the $\mathrm{PI} 3 \mathrm{~K}$ in oncogenesis includes the finding that PI3K activity is linked to viral oncogenes such as v-src (Li et al, 1997), v-abl, v-ros, ras (Chan et al, 1999). Multiple mechanisms for the activation of the PI3K-AKT/PKB pathway have been identified in a range of cancers (Mills et al, 2001, 2003). These include mutation and silencing of the pTEN tumour suppressor gene that encodes a lipid phosphatase that reverses the PI3K reaction, and amplification, overexpression and activation of the AKT/PKB. The activated AKT phosphorylates a variety of target proteins. One of these, called $\mathrm{BAD}$, is a protein that normally encourages cells to undergo apoptosis. By phosphorylating BAD, AKT inactivates it, thereby promoting cell survival (Chao and Korsmeyer, 1998). AKT also promotes cell survival by inhibiting other activators of apoptosis, in some cases by inhibiting the transcription of the genes that encode them. Various approaches are being taken to block PI3K signalling in human cancer. One strategy is to inhibit individual oncogenic kinases within the PI3K pathway. The two prototype PI3K inhibitors are wortmannin (a natural product) and the chromenone LY294002, both have shown anticancer activity in vitro and in animal models, but have significant limitation for clinical use because of the lack of kinase specificity and metabolic instability (Workman, 2003).

*Correspondence: Dr S Chan; E-mail: schan2@ncht.trent.nhs.uk Received 23 December 2003; revised 19 July 2004; accepted 29 July 2004; published online I 4 September 2004
During the mid-1990s, through molecular cloning efforts, a novel family of high molecular mass kinases whose catalytic domains bore a clear resemblance to those of PI3Ks was identified. Based on this primary sequence homology, the newly identified kinases were named PI3K and related kinases (PIKKs). The members of the PIKK family are found in all eukaryotic cells, and accumulating data from genetic, biochemical, and pharmacological studies suggest that these proteins play key roles in fundamental cellular processes, including proliferation and genome surveillance (Hartwell and Kastan, 1994; Paulovich et al, 1997). Based on primary sequence alone, it seemed reasonable to predict that the PIKKs were either lipid kinases or dual lipid - protein kinases, but the evidence that PIKKs transmit signals exclusively through the phosphorylation of protein substrate is increasing rapidly. The PIKKs includes three subfamilies: the TOR subfamily, ataxia telangiectasia, the ATM gene product, and the DNA-dependent protein kinase.

The first members of the PIKK family to be molecularly cloned were TOR1 and TOR2 from studies in budding yeast cells (Saccharomyces cerevisiae). The isolation of cDNAs encoding a mammalian ortholog, mTOR, followed shortly (Brown et al, 1994).

\section{FUNCTIONS Of THE MAMMALIAN TOR PROTEIN}

The members of the Target of Rapamycin (TOR) subfamily are uniquely targeted for inhibition by rapamycin, a feature that has greatly facilitated efforts to understand their functions in eukaryotic cells. Rapamycin is a macrolide antibiotic with antifungal and immunosuppressive properties, which has been approved as an immunosuppressant drug for organ transplantation (Abraham and Wiederrecht, 1996). Rapamycin binds to a highly conserved cytoplasmic receptor FK506-binding protein-12 (FKBP12). This FKBP12-rapamycin complex binds to and inhibits 
the kinase activities of the TOR protein subfamily, an activity not expressed by either component alone. Rapamycin's mechanism of action represents a solution for the design of a small molecule inhibitor bearing a high level of specificity for a large polypetide target. The FKBP12 receptor positions rapamycin in the optimal orientation to interact with the TOR proteins and also supplies structural determinants that contribute to the affinity and specificity of this interaction.

Studies of rapamycin-treated or TOR-depleted yeast and mammalian cells have shown that loss of TOR function leads to arrest in early G1 phase (Barbet et al, 1996). Furthermore, these cells show a severe reduction in protein synthesis resembling those cells in G0 phase, a response normally triggered by starvation. These findings suggested that the TOR proteins play a general role in the translational control of gene expression during cell growth, and the overall rate of protein synthesis in response to nutrient supply and other environmental changes.

Unlike yeast cells, mammalian cells display widely varying sensitivities to the growth-inhibition of rapamycin. A typical target cell for rapamycin is the activated $\mathrm{T}$ lymphocyte, which undergoes G1 to S phase progression in response to IL-2 or T-cell growthpromoting cytokines. IL-2-stimulated $\mathrm{T}$ cells accumulate in the mid/late G1 phase of the cell cycle in the presence of very low concentration of rapamycin (less than $10 \mathrm{~nm}$ ) (Morice et al, 1993a, b)

\section{ROLE OF mTOR IN p70 s6 KINASE ACTIVATION AND THE APPLICATION OF THE KINASE AS A BIOLOGICAL END POINT FOR CLINICAL STUDY}

There are two proteins whose phosphorylation state has been shown to be regulated by mTOR. The first targeted protein is $\mathrm{p} 70$ s6 kinase, a serine-threonine kinase that is activated in response to a broad range of mitogenic stimuli. Rapamycin blocks both the phosphorylation and activation of p70 s6K in mammalian cells. The second end point for the mTOR-dependent phosphorylation pathway is the translational-repressor protein PHAS-1 (also termed 4E-BP). Both proteins participate in the regulation of protein synthesis in cells stimulated by either mitogens or hormones.

The regulation of p70 s6k by upstream protein kinases is complex (Proud, 1996). It is clear that treatment with rapamycin quickly and efficiently inhibits the de novo phosphorylation of $\mathrm{p} 70$ s6k induced by hormonal stimuli, as well as the phosphorylation of previously activated p70 s6k. The level of p70 s6k activity in peripheral blood mononuclear cells has been showed to correlate with the efficacy of RAD001, an mTOR inhibitor in clinical studies (Lane, 2003). It has been suggested that this biomarker strategy can be used to define the minimal effective dose for clinical studies of mTOR inhibitors.

In summary, both PI3K and its downstream serine-threonine kinase AKT participate in mTOR activation by growth factors such as hormones and insulin (Gingras et al, 1998; Scott et al, 1998). This places mTOR in a signalling cascade implicated in the abnormal growth and survival of certain cancer cells. Therefore, rapamycin or other mTOR kinase inhibitors may have significant anticancer activity in tumours driven by activated PI3K or AKT or both (Dancey, 2000) (Figure 1).

\section{mTOR INHIBITORS IN CLINICAL DEVELOPMENT}

Results of clinical studies had been reported using the three rapamycin analogues: RAD001 (Novartis) (Lane, 2003), AP23573 (ARIAD Pharmaceuticals) (Mita et al, 2004), and CCI-779 (Wyeth) (Yu et al, 2001). The pharmacological action of these rapamycin analogues, like rapamycin, is mediated through its binding to the

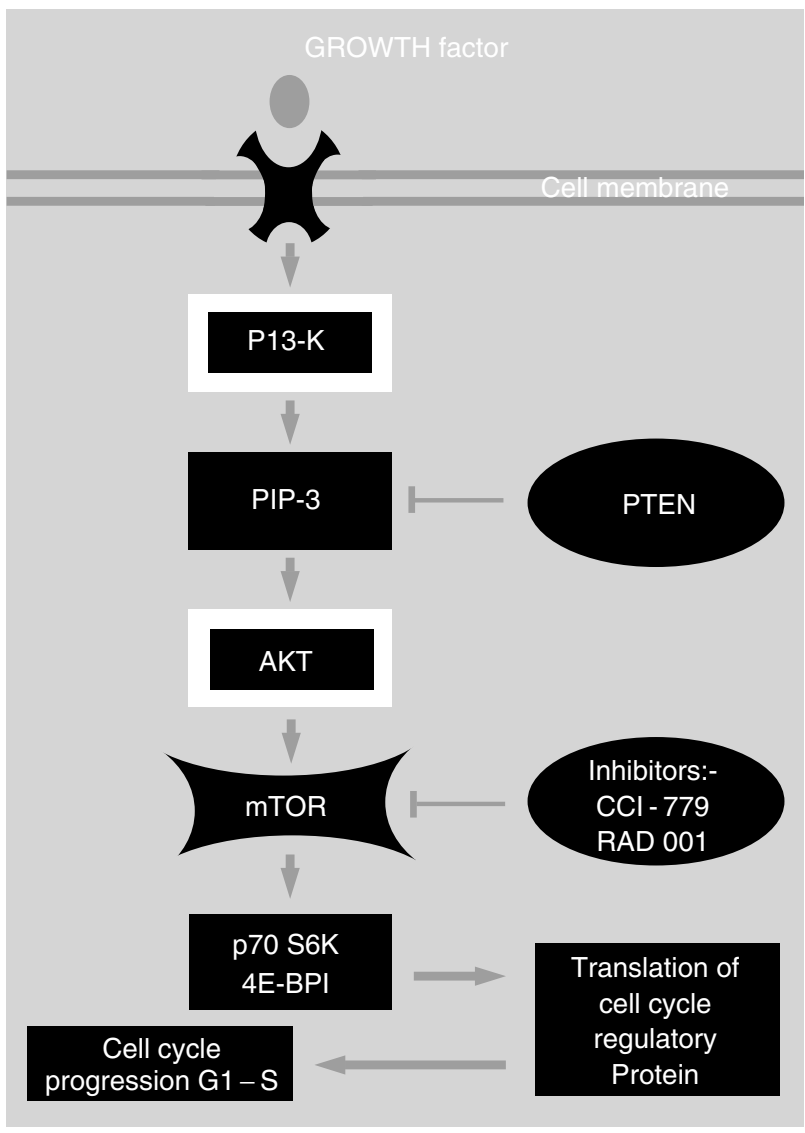

Figure I A diagram of the mTOR pathway.

intracellular protein FKBP12 and subsequent inhibition of the protein kinase $\mathrm{mTOR}$.

Sirolimus, the major metabolite of CCI-779, also binds to FKBP12. Exposure to the sirolimus metabolite is substantial, with a mean value of approximately 1.4 - to 2.3 -fold that of CCI-779 following i.v. administration to as high as 13.8 - to 34.5 -fold the values seen following oral administration. It is, at present, unclear what proportion of the anticancer activity of CCI-779 is due to CCI-779, or its metabolite sirolimus. Clinical development on the use of mTOR inhibitors in oncology is advancing rapidly. CCI-779 was the first to enter the field. Results from its clinical studies may contribute to understanding some of the challenges involved in designing trials for this group of drugs.

\section{CCI-779: preclinical studies}

A study of a panel of breast cancer cell lines showed differences in the sensitivity to the antiproliferative effects of CCI-779 (Yu et al, 2001). Sensitive cell lines were oestrogen receptor positive, or lacking in expression of the tumour suppressor gene pTEN and/or overexpression of the oncogene Her-2/neu. CCI-779 inhibited mTOR functions in both sensitive and resistant cell lines. Treatment of sensitive lines with CCI-779 resulted in a decrease in cyclin-D and c-myc levels and an increase in p27 Kip-1 levels. There was a correlation between the activation of the Akt pathway and sensitivity to CCI-779. These results suggest that mTOR may be a good target for the treatment of breast cancer. Especially in patients with tumours that are driven by the activation of the Akt pathway. The overexpression of the Akt pathway maybe due to an 
amplification of Her-2/neu oncogene, or oestrogen receptor dependence, or the loss of the pTEN tumour suppressor function.

\section{CCI-779: clinical studies}

The proposed mechanism of action by CCI-779 as an inhibitor of mTOR, and its properties as a cytostatic agent may be useful in clinical oncology. A Phase 1 study where the drug was given once a week intravenously (Alexandre et al, 1999) antitumour activity was demonstrated in patients with advanced breast cancer in the study.

\section{BREAST CANCER}

A phase 2 safety and efficacy trial of two levels of CCI-779 in women with advanced breast cancer was initiated in 2001. Enrolment was completed in February 2002 with 109 patients recruited (Chan et al, 2003a). The majority of patients received more than two lines of prior chemotherapy, including anthracyclines and/or taxanes. Results of the study were presented at the American Society of Clinical Oncology annual meeting in 2003. There was no significant difference in terms of efficacy between the patients who received 75 or $250 \mathrm{mg} \mathrm{week}^{-1}$ doses. However, toxicity was higher in the $250 \mathrm{mgweek}^{-1}$ group and a dose reduction was required in $45.1 \%$ of patients in this group compared with $28.6 \%$ in the $75 \mathrm{mg} \mathrm{week}^{-1}$ group. The most common reason for study discontinuation was lethargy and depression ( $75 \mathrm{mg}, N=5 / 42 ; 250 \mathrm{mg}, N=12 / 43$ ). Adverse events were generally grade 1 or grade 2 and often resolved without discontinuing treatment. Grade 3 and 4 toxicities were rare, and included: depression, mucositis, diarrhoea, transiently raised GGT, hyperglycaemia, hypokalaemia, leucopenia, and infection. In terms of efficacy, among the 98 evaluable patients, objective response rate (WHO criteria) was $10 \%(10 / 98)$, and the median response duration was 5.4 months (95\% CI: 3.8-7.2). Clinical benefit (partial response and stable disease over 2 months) was noted in 36 patients $(37 \%)$.

The most striking finding from the first analysis of the biological phenotype (as reported by individual centres) of those breast cancers in the study, was that none of the 32 Her-2 negative tumours showed any significant response to the treatment with CCI-779. The value of this study is the demonstration of significant clinical activity of CCI-779, with manageable toxicities, in advanced breast cancer.

We studied tumours preserved in paraffin blocks from our 28 patients who participated in the trial using immunohistochemical methods (Sharma et al, 2003). Our results showed that $4 / 28$ tumours were negative for PTEN (indicative of gene mutation), and $3 / 4$ of these tumours showed objective response to treatment with CCI-779; 3/28 tumours had HER-2 gene overexpression $(3+$ Herceptin Test or FISH + ve), 2/3 of these tumours showed an objective response to the drug. These findings suggest that PTEN mutation and/or HER-2 overexpression in breast cancer may predict response to mTOR inhibitors.

Using immunohistochemical staining of tissue microarrays, we have also studied the expression of PTEN (wild type) and its relationship with phosphorylated AKT, as well as with other recognized prognostic factors (HER-2 expression, oestrogen receptor status, histological grade, lymph node status at initial surgery, tumour size, age, menopausal status, risk of recurrence, and survival) in 429 cases of operable invasive breast cancer with a minimum 5 years of follow-up (Chan et al, 2003b). We found that $7.5 \%$ of cases did not express wild-type PTEN, while 70 and $22.5 \%$ of cases were weakly and strongly positive, respectively. The immunohistochemical expression of PTEN was related to pAKT levels $(P<0.001)$ - tumours with low levels of pAKT frequently did not express wild-type PTEN. No significant correlation was observed between PTEN and other known prognostic factors or patient survival. pAKT expression was inversely related to tumour grade $(P<0.001)$ and size $(P<0.002)$, while a positive correlation was seen with ER status $(P<0.001)$. pAkt expression was not however significantly related to patient survival nor was it an independent prognostic factor. These data suggest that the relationship between pAKT and PTEN is complicated in invasive breast cancer, and that better understanding of the pathway is necessary before we can define the predictive markers for response to treatment with the mTOR inhibitor.

The role of $\mathrm{PI} 3 \mathrm{~K} / \mathrm{AKT} / \mathrm{mTOR}$ pathway may play an important role in the development of Tamoxifen resistance in breast cancer. Activation of the oestrogen receptor can drive the PI3K pathway (Simoncini et al, 2000). Cross talk between erb-1 and ER has been shown to activate the pathway, which has been associated with oestrogen-independent transcriptional activity (Aronica and Katzellenbogen, 1991; Pietras et al, 1995; Smith, 1998; Campbell et al, 2001), and breast cancer cell lines with activated Akt is resistant to the growth inhibitory effects of Tamoxifen (Degrafenried et al, 2002). The combination of antioestrogens and mTOR inhibitors may improve the therapeutic index of either agent alone. A phase 2 study comparing the use of Letrozole with or without CCI-779 in patients with advanced breast cancer has recently completed recruitment (Baselga et al, 2004), but it is too early to assess the efficacy of this combination.

\section{RENAL CELL CARCINOMA}

In a randomised double-blind phase 2 study (Atkin et al, 2002); weekly CCI-779 at three different doses $(25 / 75 / 100 \mathrm{mg})$ was given once per week intravenously to patients with previously treated advanced renal cell carcinoma. Toxicity profile was similar to that reported from the breast cancer trial. Side effects were largely grade 1 and 2 . Overall response rate was $5 \%$. Interestingly, there was no significant difference between the three dose levels in terms of efficacy, but the $25 \mathrm{mg}$ group has the least toxicity reported.

The combination of CCI-779 and interferon alpha was studied in patients with advanced renal cell carcinoma (Dutcher et al, 2003). The result showed that the combination was well tolerated, and partial response to the treatment was observed. A large phase 3 study comparing the combination $v s$ interferon alpha alone in this patient population has already been started.

\section{OTHER CLINICAL STUDIES USING MTOR INHIBITORS: IN OTHER TUMOUR TYPES AND USED IN COMBINATIONS WITH CYTOTOXIC CHEMOTHERAPY}

Preliminary efficacy data from the phase 1 single-agent studies indicate antitumour activities (in addition to breast cancer and renal cell carcinoma) of mTOR inhibitors (CCI-779, RAD001 and AP23573) in patients with non-small-cell lung cancer, anaplastic astrocytoma, mesothelioma, soft tissue sarcoma, cervical and uterine cancer (O’Donnell et al, 2003; Mita et al, 2004).

There is evidence to suggest that mTOR inhibitors may be used to overcome drug resistance to cytotoxic chemotherapeutic agents. For example, treatment of Doxorubicin-resistant and PTEN defective prostate cancer cells with CCI-779 has been shown to reverse Doxorubicin resistance (Grunwald et al, 2002). There is no clinical data available on this combination, at the present. CCI-779 combinations with Gemcitabine and 5-Fluorouracil (+ Leucovorin) were limited by gastrointestinal events (diarrhoea, mucositis, and nausea). In combination with Gemcitabine (day 1 and 8 of 21days cycle), the maximum tolerated dose of CCI-779 was only $15 \mathrm{mg}$ per sq $\mathrm{m}$, and the weekly i.v. dose in the 5Fluorourcil combination was $75 \mathrm{mg}$ per sq $\mathrm{m}$ (Wyeth, personal communication). 


\section{SUMMARY}

The mTOR inhibitors have demonstrated clinical activities in a broad spectrum of solid tumours. Unresolved challenges to researchers include: definition of the optimal dose and scheduling; identifying the appropriate biological end points for dose finding studies; finding predictive markers for tumour phenotypes likely to response to mTOR inhibitors; and finding optimal combination treatment with other drugs and radiotherapy. Drug development targeting the mTOR pathway looks exciting, but a lot more work remains to be done.

\section{REFERENCES}

Abraham RT, Wiederrecht GJ (1996) Immunopharmacology of rapamycin. Annu Rev Immunol 14: 483-510

Alexandre J, Raymond E, Depenbrock H (1999) CCI-779, a new rapamycin analog, has antitumour activity at doses inducing only mild cutaneous effects and mucositis: early results of an ongoing phase 1 study. Proceedings of the AACR/NCI/EORTC International Conference on Molecular Targets and Cancer Therapeutics. Washington, DC, November $16-19$

Aronica SM, Katzellenbogen B (1991) Progestrogene receptor regulation in uterine cells: stimulation by oestrogen, cyclic adenosine 3,5-monophosphate, and insulin like growth factor I and suppression by antioestrogens and protein kinase inhibitors. Endocrinology 128: 2045-2052

Atkin MB, Hidalgo M, Stadler W, Logan T, Dutcher JP, Hudes G, Park Y, Marshall B, Boni J, Dukart G (2002) A randomises phase 2 study of intravenous CCI-779 administered weekly to patients with advanced renal cell carcinoma. Meeting Proceedings American Society of Clinical Oncology: vol 21: Poster Presentation Abst 36

Barbet NC, Schneider U, Helliwell SB, Stansfield I, Tuite MF, Hall MN (1996) TOR controls translation initiation and early G1 progression in yeast. Mol Biol Cell 7: 25-42

Baselga J, Fumoleau P, Gil M, Colomer H, Roche H, Cortes-Funes H, Burstein H, Kaufman P, Kong S, Moore L (2004) Phase 2, 3-arm study of CCI-779 in combination with Letrozole in postmenopausal women with locally advanced or metastatic breast cancer: preliminary results. Meeting Proceedings American Society of Clinical Oncology: vol 23: Poster Presentation Abst 544

Brown EJ, Albers MW, Shin TB, Ichikawa K, Keith CT, Lane WS, Schreiber SL (1994) A mammalian protein target by G1-arresting rapamycinreceptor complex. Nature 369: 756-758

Campbell RA, Bhat-Nakshatri P, Patel NM, Constantinidou D, Simak A, Nakshatri H (2001) Phosphatidyl-insostol-3-kinase/Akt mediated activation of oestrogen alpha: a new model for anti-oestrogen resistance. J Biol Chem 276: $9817-9824$

Chan S, Scheulen ME, Johnston S, Mross K, Piccart M, Hess D, Bouxin N, Azali N, for the European CCI-779 Breast Group (2003a) Phase 2 study of two dose levels of CCI-779 in locally advanced or metastatic cancer (MBC) failing prior anthracycline and/or taxane regimens. Meeting Proceedings American Society of Clinical Oncology: vol 22; Oral Presentation Abst 774

Chan SY, Panigrahi AR, Pinder SE, Sharma R, Ellis IO, Robertson JFR, on behalf of the Nottingham Breast Team (2003b) Imunohistochemical study of the PTEN/AKT pathway in early and advanced breast cancer. Program and Proceedings of AACR-NCI-EORTC Internal Conference: Molecular Targets and Cancer Therapeutics Abst B 167, p 159, Boston, MA: Hynes Center

Chan TO, Rittenhouse SE, Tsichlis PN (1999) AKT/PKB and other D3 phosphoinositide-regulated kinases: kinase activation by phosphoinositide-dependent phosphorylation. Annu Rev Biochem 68: 965-1014

Chao DT, Korsmeyer SJ (1998) BCL-2 family: regulators of cell death. Annu Rev Immunol 16: 395-419

Dancey JE (2000) Rapamycin-sensitive signal-transduction pathway: protein transduction control of cell proliferation. American Society of Clinical Oncology Educational Book, ASCO 36th annual meeting, New Orleans, LA. pp 68-75

Degrafenried L, Friedrichs W, Fulcher L, Silva J, Roth R, Hidalgo M (2002) The mTOR inhibitor CCI-779 restores Tamoxifen response in breast cancer cells with high Akt activity. 14th NCI-EORTC-AACR symposium on molecular targets and cancer therapeutics. Eur J Cancer 158, abst 528

Dutcher JP, Hudes G, Motzer R, Ko Yj, Smith JW, Zono K, Marhall B, Dukart G, Liou SH (2003) Preliminary report of a phase 1 study of intravenous CCI-779 given in combination with interferon alpa to patients with advanced renal cell carcinoma. Meeting Proceedings
American Society of Clinical Oncology: vol 22: Poster Presentation Abst 854

Gingras AC, Kennedy SG, O'Leary MA, Sonenberg N, Hay N (1998) 4E-BP1, a repressor of mRNA translation is phosphorylated and inactivated by the Akt (PKB) signalling pathway. Genes Dev 12: 502-513

Grunwald V, Degrafenried L, Russel D (2002) Inhibitor of mTOR reverses doxorubicin resistance conferred by PTEN status in prostate cancer cells. Cancer Res 62: 6141-6145

Hartwell LH, Kastan MB (1994) Cell cycle control and cancer. Science 266: $1821-1828$

Lane HA (2003) The Rapamycin derivative RAD001 in oncology: what is the endpoint? Program and Proceedings of AACR-NCI-EORTC Internal Conference. Molecular Targets and Cancer Therapeutics November 1721, Abst Book, pp 259-260, Boston, MA: Hynes Center

Li Z, Wahl MI, Eguinoa A, Stephens LR, Hawkins PT, Witte ON (1997) Phosphatidylinositol 3-kinase-gamma activates Bruton's tyrosine kinase in concert with Src family kinases. Proc Natl Acad Sci USA 94: $13,820-13,825$

Mills GB, Kohn E, Lu Y, Eder A, Fang X, Wang H, Bast RC, Gray J, Jaffe R, Hortobagyi G (2003) Linking molecular diagnostics to molecular therapeutics: targeting the PI3K pathway in breast cancer. Semin Oncol 30(5 Suppl 16): $93-104$

Mills GB, Lu Y, Fang X, Wang H, Eder A, Muling M, Swaby R, Cheng KW, Stokoe D, Siminovitch K, Jaffe R, Gray J (2001) The role of genetic abnormalities of PTEN and the phosphatidylinositol 3-kinase pathway in breast and ovarian tumorigenesis, prognosis and therapy. Semin Oncol 28: $125-141$

Mita MM, Rowinsky EK, Goldston ML, Mita AC, Chu Q, Syed S, Knowles HL, Rivera VM, Bedrosian CL, Tolcher AW (2004) Phase 1 pharmacokinetic (PK) and pharmacodynamic (PD) study of AP23573 an mTOR inhibitor administered IV daily $\times 5$ every other week in patients with refractory or advanced malignancies. Meeting Proceedings American Society of Clinical Oncology: vol 23: Poster Presetnation Abst 3076

Morice WG, Brunn GJ, Wiederrecht G, Siekierka JJ, Abraham RT (1993a) Rapamycin-induced inhibition of p34cdc2 kinase activation is associated with G1/S-phase growth arrest in T lymphocytes. J Biol Chem 268: $3734-3738$

Morice WG, Wiederrecht G, Brunn GJ, Siekierka JJ, Abraham RT (1993b) Rapamycin inhibition of interleukin-2-dependent p33cdk2 and p34cdc2 kinase activation in T lymphocytes. J Biol Chem 268(22): $737-745$

O’Donnell A, Faivre S, Judson I, Delbado C, Brock C, Lane H, Shand N, Hazell K, Armand JP, Raymond E (2003) A phase 1 study of the oral mTOR inhibitor RAD001 as monotherapy to identify the optimal biological effective dose using toxicity, pharmacokinetic(PK) pharmacodynamic (PD) endpoints in patients with solid tumours. Meeting Proceedings American Society of Clinical Oncology: vol 22: Poster Presentation Abst 803

Paulovich AG, Toczski DP, Hartwell LH (1997) When checkpoints fail. Cell 88: $315-321$

Pietras RJ, Arbodela J, Reese DM, Wongvipat N, Pegram M, Ramoss L, Gorman CM, Parker MG, Sliwkowski MX, Slamon DJ (1995) Her-2 tyrosine kinase pathway targets oestrogen receptor promotes hormone independent growth in human breast cancer cells. Oncogene 10: $2435-2446$

Proud CG (1996) P70 s6 kinase: an enigma with variations. Trends Biochem Sci 21: $181-185$

Scott PH, Brunn GJ, Kohn AD, Roth RA, Lawrence JC (1998) Evidence of insulin-stimulated phosphorylation and activation of mammalian target of rapamycin by a protein kinase B signalling pathway. Proc Natl Acad Sci USA 95: $7772-7777$

Sharma R, Pinder SE, Ellis IO, Paish C, Chan SY (2003) 8th Nottingham International Breast Cancer Conference. Abst 55, Eur J Can Suppl 1(4) 
Simoncini T, Haferzi-Moghadam A, Brazil DP, Ley K, Chin WW, Liao JK (2000) Interaction of oestrogen receptor with the regulatory subunit of Phosphatidyl-insostol-3-OH-kinase. Nature 407: $538-541$

Smith CL (1998) Cross-talk between peptide growth factor and oestrogen receptor signalling pathways. Biol Reprod 58: $627-632$
Workman P (2003) 'Drugging the PI3K pathway' Program and Proceedings of AACR-NCI-EORTC Internal Conference. Molecular Targets and Cancer Therapeutic Abst Book, pp 257-258, Boston, MA: Hynes Center

Yu K, Toral-Barza L, Discafani C, Zhang WG, Skotnicki J, Frost P, Gibbons JJ (2001) mTOR, a novel target in breast cancer: the effect of CCI-779, an mTOR inhibitor, in preclinical models of breast cancer. Endocrine-Relat Cancer 8: $249-258$ 